\title{
Stem the Tide of Predatory Stem Cell Clinics: State and FDA Coordination to Protect Patients
}

\section{Griffin McCutcheon ${ }^{1,2,3}$, John F. Malloy ${ }^{1,4}$, Caitlyn A. Hall ${ }^{1,5}$,} Cassandra Barrett 1,6

\author{
${ }^{1}$ Arizona Science Policy Network \\ ${ }^{2}$ Arizona State University, School for Engineering of Matter, Transport, and Energy, Tempe AZ \\ ${ }^{3}$ Arizona State University, School for Health and Biological Systems Engineering, Tempe AZ \\ ${ }^{4}$ Arizona State University, School of Earth and Space Exploration, Tempe AZ \\ ${ }^{5}$ Arizona State University, Sustainable Engineering and the Built Environment, Tempe AZ \\ 6University of Utah, Eccles Institute of Human Genetics, Salt Lake City, UT \\ http://doi.org/10.38126/JSPG170114 \\ Corresponding author: gmccutch@asu.edu
}

Key Words: stem cell, public health, FDA, state regulation, medicine

\begin{abstract}
Executive Summary
While stem cell therapies hold promise as regenerative treatments for combating a variety of conditions, the majority of these therapies remain in clinical trials without sufficient evidence for current clinical use. Predatory direct-to-consumer stem cell clinics (hereafter, DTC clinics), undeterred by a lack of clinical evidence, continue to offer unapproved stem cell injections to patients desperate to treat chronic conditions. These clinics can pose significant physical and financial harm to patients as their therapies are not without risks. Clinics rarely practice the requisite level of follow-up care required by clinical trials. To promote the safety and well-being of patients treated in stem cell clinics, we propose additional funding to support the Federal Food and Drug Administration (FDA) and state-level health departments' oversight of DTC clinics. The FDA will likely experience a substantial financial burden from enforcing regulations, given that there are hundreds of DTC clinics in the U.S. This number is expected to continue rising, as evidenced by a 114\% increase in DTC clinics between 2015 and 2017 (P. S. Knoepfler 2019). We propose that the FDA appropriate additional funding to support state level government enforcement and address this impending shortcoming. Additionally, we suggest state legislatures enact registry laws to prevent DTC clinics from avoiding federal regulations and enable local governments to address low-risk offenders as needed. These laws would enable states to take a more proactive role in patient protections, while also allowing the FDA to more effectively target its resources towards high-risk DTC business.
\end{abstract}

\section{The rise and risks of unregulated stem cell clinics}

Within emerging fields of medicine, few are as exciting, complex, and promising as regenerative medicine through stem cells. Researchers are investigating the potential for stem cells to address perennially challenging issues through organ regrowth, spinal cord repair, and damaged tissue regeneration (Office of the Commissioner 2019a). FDA approved clinical trials are required to ensure that new medical interventions are safe, efficacious, and improve patients' health (21 U.S.C. $356 \S 506(\mathrm{~g})$ ). The clinical trials approval process occurs in a series of sequential stages to assess safety, optimize 
treatment, experimentally verify efficacy, and identify potential risks. To date, the FDA has only approved stem cell therapies for use in therapeutic bone marrow transplants (Center for Biologics Evaluation and Research 2019).

Despite the lack of FDA approval, the allure of profits from stem cell therapies have sparked a growing industry of DTC clinics that advertise and provide non-FDA approved therapies. These clinics often employ predatory practices by targeting patients with chronic or severe conditions that have complex or multifactorial etiologies for which conventional, evidence-based therapy options may have run out (Frow et al. 2019) such as cancer, hepatitis, neurodegeneration and vision loss (Kimbrel and Lanza 2020). Insurance companies typically will not cover non-FDA approved treatments, leading to crowdfunding campaigns by desperate patients (Snyder, Turner, and Crooks 2018), which result in individuals paying anywhere from $\$ 2,500$ to over $\$ 50,000$ per non-regulated stem cell injection (P. Knoepfler 2019). Moreover, unregulated treatments performed by these facilities have led to medical malpractice and harm to patients, such as induced blindness due to negligent cell-handling practices and a tumor from directly injecting cells into the spine (Kuriyan et al. 2017).

Without a rigorous clinical trial process, premature use of stem cell technology puts the patients' health at risk while leaving the potential benefits from stem cell treatments uncomfirmed. DTC clinics mislead the public by portraying their treatments as less risky compared to the uncertainty of clinical trials or other treatments (Snyder, Turner, and Crooks 2018). But as the malpractice shows, premature use of stem cell technology without regulation or follow up care puts the patients' health at even more risk. DTC clinics have falsely claimed that if the stem cells are a patients' own, FDA approval is not required, along with numerous false and/or misleading claims that their products are approved to treat serious and life threatening diseases (Office of the Commissioner 2019b). The Federal Trade Commission (FTC) has successfully sued companies for this type of misrepresentation (Federal Trade Commission 2018), but companies continue to advertise such claims. While promising research shows stem cells may treat cancer, diabetes, macular degeneration, Parkinson's, and much more (Kimbrel and Lanza
2020), these treatments are not yet fully developed nor FDA-approved and are inherently more risky. DTC clinics and their practices risk causing distrust of legitimate stem cell clinical trials and healthcare providers, while financially harming vulnerable patients (P. Knoepfler 2015).

DTC clinics also attempt to avoid medical facility regulation. Healthcare facilities are typically licensed and monitored by a state's department of health to meet standard levels of care through inspections, onsite surveys, and complaint investigations ("The Future of Public Health" 1988, Gostin et al. 1999). But DTC clinics attempt to legally insulate themselves by co-locating with other healthcare facilities to avoid registering with the state, making monitoring and regulation difficult at both state and federal levels (Frow et al. 2019). Florida has proposed laws to eliminate these legal grey areas and bring DTC clinics under the jurisdiction of state departments of health, requiring any businesses providing non-embryonic stem cells to register as health care clinics ("Senate Bill 512 (2020) - The Florida Senate" n.d.). However, no concerted effort to increase state oversight among all states exists as of this writing.

\section{Existing regulations and precedents on stem cell therapies}

The FDA is the primary federal body that regulates regenerative medicine, stem cell therapies, and clinical trials. These powers are endowed through the Federal Food, Drug, and Cosmetic Act (21 U.S.C. $356 \S$ 506(g)), the Public Health Safety Act (42 U.S.C. $262 \S$ 351), and the 21st Century Cures Act (Pub. L. 114255, 130 Stat. 1033). The FDA reviews new stem cell treatment submissions as Investigational New Drugs (IND) (Fink 2009). The FTC also affects DTC stem cell clinics as it oversees misleading marketing and advertising (15 U.S.C. $§ \S 45(a)$ and 52). While the FDA provides guidelines for regenerative medicine programs and expedited treatment approval (Sharpless and Marks, 2019; 21 U.S.C. 356 § 506(g)), these do not translate directly to enforcement power.

Court rulings have been the primary mechanism to enforce authority and set boundaries for stem cell regulation by the FDA (Sharpless and Marks, 2019). In 2012, a court ruled that stem cell therapies are a biological treatment that should be regulated as a drug by the FDA, thereby establishing the agency's oversight and enforcement authority through law 
rather than solely legal precedent (United States v. Regenerative Sciences, LLC). In 2019, a federal court ruling in United States v. US Stem Cell Clinic, LLC, granted the FDA the ability to prevent a Florida-based DTC clinic from offering treatments shown to be ineffective and potentially harmful (Office of the Commissioner 2019a).

\section{Proposed collaborative policy solutions}

Although the FDA has announced its intention to increase enforcement against DTC clinics (Office of the Commissioner 2018), it faces inadequate resources and poor talent acquisition and retention in its drug oversight department ("FDA 21st Century Cures Workforce Planning Report to Congress" 2018). Overseeing the large number of noncompliant DTC clinics would add a significant additional burden without additional funding ("FDA's Framework for Regulating Regenerative Medicine Will Improve Oversight" n.d.). In order to prevent DTC clinics from causing harm to potential patients through unregulated treatments, we propose:

1) U.S. Congress appropriates funds to the FDA for registering, regulating, and enforcing DTC clinics in conjunction with state authorities;

2) States pass legislation requiring all DTC clinics, regardless of treatment method, to register with state governments;

3) Federal- and state-level agencies augment their databases of clinics to include those practicing regenerative medicine and stem cell therapies.

\section{i. Overview of proposed solutions}

The FDA and FTC are respectively empowered to regulate stem cell products and their advertising at the national level, but enforcement occurs through judicial decisions at the state level. Therefore, we recommend a proactive mix of federal- and statelevel actions to better regulate DTC clinics with the aim of preventing malpractice and physical or financial harm to patients (Figure 1).

In this proposed system, the U.S. Congress would appropriate funds to the FDA. The FDA would then distribute the funds, contingent upon states increasing local oversight efforts which are described below. Funding amount would depend on state needs as DTC clinics are not uniformly distributed throughout the states. As of 2016, California and Florida had over fifty clinics each, while nineteen

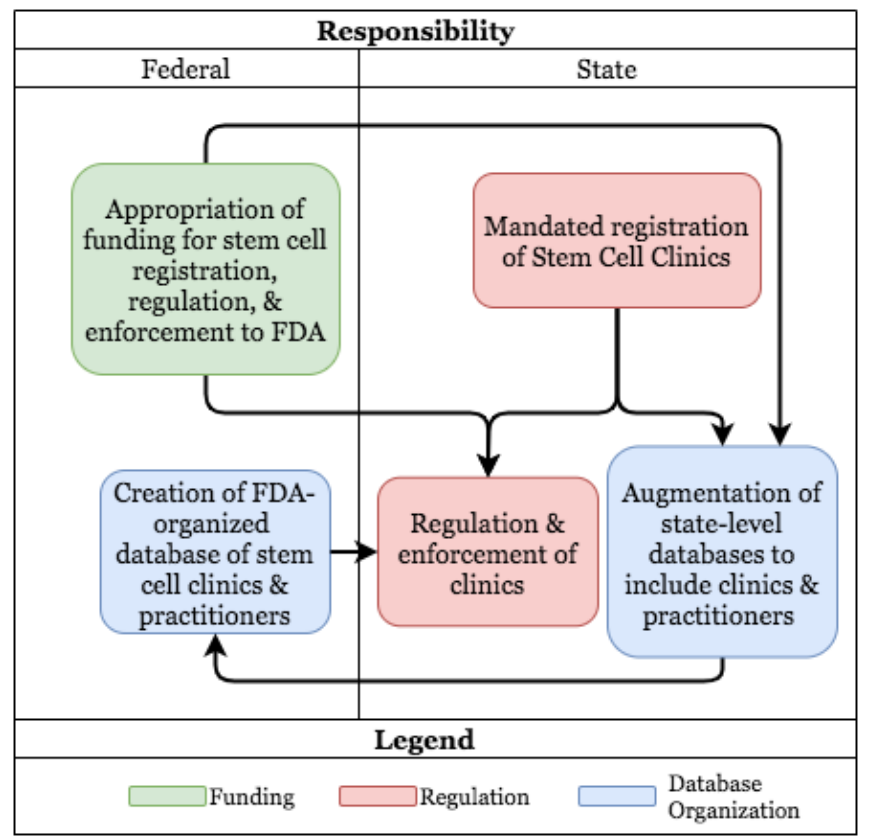

Figure 1. Policy recommendation linking appropriation of funding to FDA with mandated registration, regulation, and enforcement of direct-to-consumer stem cell clinics on both a state and federal level.

states were home to less than two (Berger et al. 2016).

We recommend increased state regulatory action through laws similar to those proposed in Florida ("Senate Bill 512 (2020) - The Florida Senate" n.d.). Such a bill would require businesses offering any stem cell therapies and products to register with the state's existing healthcare licensing framework. The law would apply to businesses that are not pursuing FDA-monitored IND research and mandate that the resultant databases be made accessible to the FDA. The goal of such laws is to enable state health departments to track DTC clinics and provide clear legal means by which state authorities can shut down those attempting to skirt regulatory action. Integration of local registration data into federal databases will also enable the FDA to more easily identify non-compliant DTC clinics and coordinate with state health and legal departments for legal action. Similar to current regulatory standards, repercussions for non-compliance should initially be fines levied on non-compliant DTC clinics, but increase in severity to lawsuits and potential probation, suspension, or revocation of healthcare provider licenses by state licensing boards. In this 
manner, state governments can address clinics with predatory practices such as advertising false medical claims without relying as heavily on overstretched federal agencies. DTC clinic registration laws alone may prove a deterrent from such practices, resulting in a relatively low-cost public health improvement. This also frees up FDA personnel to focus on high risk providers such as those illegally testing experimental treatments.

\section{ii. Recommendation 1: U.S. Congressional funding}

As the registration and partial regulation for DTC clinics would occur on the state level, federal funding would be allocated through the FDA to each states' Department of Health (or equivalent agency) to encourage adoption of FDA recommendations and assist federal regulation. Specifically, we recommend allocating federal funding to establish a formulaproject categorical grant (Congressional Research Service, 2019) to states. This grant will provide baseline funding for states to update and administer certification practices (detailed in Recommendation 3) and fund personnel for oversight and enforcement. The funding amount provided to states will increase as the number of registered DTC clinics within a state increases to allow continued oversight of these clinics. Without these financial resources, states may be unlikely to adopt and enact these necessary measures.

\section{iii. Recommendation 2: State legislation}

State-level legislation should promote patient wellbeing by allowing state authorities to regulate DTC clinics. Legislation should achieve the following:

- Define the terms relating to obtaining, manufacturing, storing, culturing, dispensing, delivering, and administering adult human non-embryonic stem cells and Human Cells, Tissues, and Cellular and Tissue-Based Products (HCT/P's);

- Designate that all facilities that administer adult human non-embryonic stem cells to patients and/or clients are healthcare facilities. All healthcare facilities must meet current licensure requirements, and any additional requirements to be provided by the licensing department, or face disciplinary action;

- Require a state's respective Department of Health (or equivalent licensing body) to include in their licensing a record of the following: whether a health care facility uses adult human non-embryonic stem cells, whether these cells are derived from human tissue from one's own body, and whether these cells are intended for implantation, transplantation, infusion, or transfer into a human recipient;

- Encourage relevant state departments to establish rules and pursue action such as monitoring advertising, procedures and protocols, incident reporting, informed consent, and recordkeeping consistent with federal regulations.

\section{iv. Recommendation 3: Database development and} augmentation

States require a licensure application for medical facilities, though their power and scope vary ("The Future of Public Health" 1988, Gostin et al. 1999). Through the grant specified above in Recommendation 1, states will be required to modify these licensure records through the simple addition of a checkbox (or equivalent indicator) to the standard form inquiring if a clinic produces or provides stem cell therapies. This would provide the necessary data for monitoring stem cell facilities to current registries. With this addition, states can track the number and location of DTC clinics without creating an undue burden on either existing healthcare providers or the state's medical administration infrastructure. The failure of a DTC clinic to register as offering stem cell therapy will result in increased penalties, beginning with fines and potentially resulting in license revocation for staff.

State-level registry data pertaining to DTC clinics should be made public, such that the individual patient has access to make informed health decisions. This would also allow the FDA access for regulatory purposes. Registration data should be placed into an easily accessible and searchable digital format to encourage cooperative enforcement and allocation of further federal funding. This proposed system structure has been shown to be effective by similar programs such as the Clinical Laboratory Improvement Amendments (42 U.S.C. § 263a), which ensures consistent regulation of human sample testing across states (Ehrmeyer and Laessig 2004). 


\section{Challenges}

One potential challenge of this law is identifying DTC clinics that register as different business types or names to evade scrutiny, as studies of these businesses have shown (Frow et al. 2019). However, state health departments can still identify these newly rebranded businesses and identify if any staff or providers have had previous or on-going employment at a clinic undergoing investigation. Thereby, the state health departments are better equipped to mitigate fraudulent practices. Upon discovery of DTC clinics posing as different wellness businesses, state-level governments can pursue enforcement against these clinics.

Differences in oversight programs across states combined with the nationwide prevalence of DTC clinics will pose a challenge to coordination with federal agencies. States have unequal enforcement

\section{References}

Berger, Israel, Amina Ahmad, Akhil Bansal, Tanvir Kapoor, Douglas Sipp, and John E. J. Rasko. 2016. "Global Distribution of Businesses Marketing Stem CellBased Interventions." Cell Stem Cell 19 (2): 15862. https://doi.org/10.1016/i.stem.2016.07.015.

Center for Biologics Evaluation, and Research. 2019. "Approved Cellular and Gene Therapy Products." U.S. Food and Drug Administration. 2019. https://www.fda.gov/vaccines-blood-

biologics/cellular-gene-therapyproducts/approved-cellular-and-gene-therapyproducts.

Ehrmeyer, Sharon S., and Ronald H. Laessig. 2004. "Has Compliance with CLIA Requirements Really Improved Quality in US Clinical Laboratories?" Clinica Chimica Acta; International Journal of Clinical Chemistry 346 (1): 37-43. https://doi.org/10.1016/j.cccn.2003.12.033.

"FDA's Framework for Regulating Regenerative Medicine Will Improve Oversight." n.d. Accessed April 13, 2020. https://www.pewtrusts.org/en/researchandanalysis/reports/2019/10/17/fdas-

framework-for-regulating-regenerativemedicine-will-improve-oversight.

Fink, Donald W., Jr. 2009. "FDA Regulation of Stem CellBased Products." Science 324. https://doi.org/10.1126/science.1173712 capabilities and different burdens of need. Such challenges are unavoidable when merging state and federal efforts. However, an overarching federal program alone is ill-suited to address the issue of harmful DTC clinics because of the variation in needs between each state. For example, a state with dozens of DTC clinics across a variety of medical fields would require a different regulatory process than a state with less than ten clinics. Likewise, a solely state-level program's jurisdiction is too limited.

We propose that a collaborative effort is more likely to effectively protect patients from DTC clinics and would be the most optimal use of appropriated funds. Funding appropriation will be carried out on the federal level, while enforcement will be carried out on the state level. Federal oversight will also create the DTC database, which states will augment, resulting in effective oversight of DTC clinics.

Frow, Emma K., David A. Brafman, Anna Muldoon, Logan Krum, Paige Williams, Bryson Becker, John P. Nelson, and Ashley Pritchett. 2019. "Characterizing Direct-to-Consumer Stem Cell Businesses in the Southwest United States." Stem Cell Reports 13 (2): 247-53. https://doi.org/10.1016/j.stemcr.2019.07.001.

Gostin, Lawrence 0., Scott Burris, and Zita Lazzarini. "The Law and the Public's Health: A Study of Infectious Disease Law in the United States." Columbia Law Review 99, no. 1 (1999): 59-128. Accessed August 18, 2020. https://doi:10.2307/1123597.

Institute of Medicine (US) Committee for the Study of the Future of Public Health. The Future of Public Health. Washington (DC): National Academies Press (US); 1988. https://doi: 10.17226/1091

Kimbrel, Erin A., and Robert Lanza. 2020. "Next-Generation Stem Cells-ushering in a New Era of Cell-Based Therapies." Nature Reviews. Drug Discovery, 117. https://doi.org/10.1038/s41573-020-0064-x

Knoepfler, Paul. 2015. "David Brafman Guest Post: A Look Inside a Stem Cell Clinic Infomercial Event - The Niche." The Niche. April 29, 2015. https://ipscell.com/2015/04/lunginstitute/.

Knoepfler, Paul. 2019. "How Much Is Stem Cell Therapy? 2019 Cost Poll Results - The Niche." The Niche. October 13, 2019. https://ipscell.com/2019/10/how-much-isstem-cell-therapy-2019-cost-poll-results/.

Knoepfler, Paul S. 2019. "Rapid Change of a Cohort of 570 Unproven Stem Cell Clinics in the USA over 3 Years." Regenerative Medicine 14 (8): 735-40. https://doi.org/10.2217/rme-2019-0064. 
Kuriyan, Ajay E., Thomas A. Albini, Justin H. Townsend, Marianeli Rodriguez, Hemang K. Pandya, Robert E. Leonard, M. Brandon Parrott, Philip J. Rosenfeld, Harry W. Flynn, and Jeffrey L. Goldberg. 2017. "Vision Loss after Intravitreal Injection of Autologous 'Stem Cells' for AMD." The New England Journal of Medicine 376 (11): 1047-53. https://doi.org/10.1056/NEJMoa1609583.

Office of the Commissioner. 2018. "FDA Sends Warning to Company for Marketing Dangerous Unapproved Stem Cell Products That Put Patients at Risk and Puts Other Stem Cell Firms, Providers on Notice." U.S. Food and Drug Administration. 2018. https://www.fda.gov/news-events/pressannouncements/fda-sends-warning-companymarketing-dangerous-unapproved-stem-cellproducts-put-patients-risk-and.

Office of the Commissioner. 2019a. "Statement on Stem Cell Clinic Permanent Injunction and FDA's Ongoing Efforts to Protect Patients from Risks of Unapproved Products." U.S. Food and Drug Administration. 2019. https://www.fda.gov/news-events/pressannouncements/statement-stem-cell-clinicpermanent-injunction-and-fdas-ongoing-effortsprotect-patients-risks.

Office of the Commissioner. 2019b. "FDA Warns About Stem Cell Therapies." U.S. Food and Drug Administration. April 9, 2019. https://www.fda.gov/consumers/consumerupdates/fda-warns-about-stem-cell-therapies.
"Senate Bill 512 (2020) - The Florida Senate." n.d. Accessed April 13, 2020. https://www.flsenate.gov/Session/Bill/2020/51 2/

Snyder, Jeremy, Leigh Turner, and Valorie A. Crooks. 2018. "Crowdfunding for Unproven Stem Cell-Based Interventions." JAMA: The Journal of the American Medical Association 319 (18): 1935-36. https://doi.org/10.1001/jama.2018.3057.

Federal Trade Commission. 2018. "FTC Stops Deceptive Health Claims by a Stem Cell Therapy Clinic". October 18, 2018. Accessed July 172020. https://www.ftc.gov/news-events/pressreleases/2018/10/ftc-stops-deceptive-healthclaims-stem-cell-therapy-clinic.

U.S. Food and Drug Administration, "FDA in Brief: FDA Launches New Campaign to Advance Ongoing Efforts to Recruit and Retain a World-Class Workforce Dedicated to Protecting and Promoting the Public Health," news release, July 24, 2018, https://www.fda.gov/NewsEvents/Newsroom/F DAInBrief/ucm614567.htm.

U.S. Food and Drug Administration, "FDA 21st Century Cures Workforce Planning Report to Congress" (2018).

Griffin McCutcheon (he/his) is a Ph.D. candidate in the Biological Design Program at Arizona State University. He designs genetic control systems and studies how they can be integrated with biological self-assembly for new methods of nanoparticle fabrication. He is also co-chair of the Arizona Science Policy Network, helping students find their voice and craft values-based policy that leverages their scientific expertise. He enjoys mountain biking the desert trails, woodworking, and being a dog dad to his two pups.

John F. Malloy (he/him) is a Ph.D. candidate studying Astrobiology and Complex Systems Science at Arizona State University in the School of Earth and Space Exploration. He studies the fundamental nature and definition of life, both on Earth and on other planets, through exploring the evolution of life and life-like systems. He is working to predict future evolutionary steps and create a universal definition of evolution. He is also a member of the Arizona Science Policy Network, where he works to advance science-based policy measures in Arizona. He enjoys training for and competing in ultramarathons across the American Southwest.

Caitlyn A. Hall (she/her/they/them) is a founding member of the Arizona Science Policy Network and a Ph.D. student in Environmental Engineering at Arizona State University. Her current research promotes climate change and natural hazard resilience in communities using microbes to reduce damage from earthquakeinduced liquefaction. She works with industry, community, and government leaders to develop best-fit technical, policy, and public health solutions to best-address a community's challenges and values. Her other research has focused on soil and water remediation, and sustainable use of resources for urban and greenhouse crop production and agriculture. For fun, Caitlyn spends her time rock climbing and trail running. 
Dr. Cassandra Barrett (she/her/they/them) is a founding member of the Arizona Science Policy Network and holds a Ph.D. in Biological Design from Arizona State University. She is currently retraining as a genetic counselor at the University of Utah to help integrate patient needs into innovation pipelines. Her research is focused on gene therapy implementation and developing best practices for centering patient perspectives within technology development. She is committed to the ethical advancement of genetic medicines and testing through engagement, communication, and innovation. Cassandra is an avid baker, print maker, and poet.

\section{Acknowledgements}

We would like to thank Dr. Nicholas Weller for his review and feedback during the drafting of this memo.

\section{Disclaimer}

This memo represents the views and assessments of the authors, not the views of their affiliates, departments, or institutions. 